\title{
Lobenhoffer Philipp (ed.): Osteotomies around the knee. Indications: planning: surgical techniques using plate fixators
}

\author{
Hardcover, 2008, 278 pp, number illustration Euro (D) 159.95 CHF: 266.00, \\ ISBN: 978-3-13-147531-2
}

\author{
Pierre Kehr
}

Received: 28 February 2010 / Accepted: 1 March 2010 / Published online: 12 March 2010

(c) Springer-Verlag 2010

It is about one very beautiful book, co-edited by Swiss, German and Dutch surgeons, under the aegis of AO foundation. This book presents a little unusual format but with a binding of excellent quality, a clear page layout and multiple illustrations and tables throughout its 280 pages.

The plan logical, very well is structured and largely covers all the field announced in the title. Each chapter well is built and followed of a completely satisfactory bibliography.

The strong points of the book are the study of the history, of the clinical and radiological bases of the deformations of the knee, the surgical indications and the preoperative planning of the operations. All this is extremely well done for the greatest benefit of any operator called to make osteotomies, techniques currently again in renewal of growth.

The chapters treating the clinical applications are also completely correct but fish by the recourse to the nearly exclusive use of a plate developed at the point by the AO Research Institute of Davos, this explaining that. However, the drafting of these chapters concerning the various clini- cal techniques is of good invoice; but one can only regret the absence of comparison with other techniques, or even with other plates (put aside only one example right city).

The chapters concerning the problems are particularly interesting which can pose the installation of a prosthesis after an osteotomy, the assumption of responsibility of the complications of the osteotomies and the recoveries no-prosthetic for failure of osteotomy, with quite practical receipts to use.

The book ends in a prospective sight on the interest of navigation, on possible progress still in the material of osteosynthesis but is unaware of almost completely while making only quote them (as throughout the book) the osseous substitutes of synthesis in the filling of the space with opening osteotomies.

Claude Schwartz Colmar (France)

No funds were received in support of this study.

P. Kehr (四)

SOTEST, Strasbourg, France

e-mail: kehrpier@aol.com 